\title{
Study on Development Strategy of National Emergency Communication Engineering
}

\author{
Xuan Deng ${ }^{1}$ Yinghua Song ${ }^{2}$ \\ ${ }^{1}$ School of Management, Wuhan University of Technology, Wuhan, China, 430070 \\ ${ }^{2}$ School of Management, Wuhan University of Technology, Wuhan, China, 430070
}

\begin{abstract}
Emergency communication engineering engages communication technology into emergency management and thus enhances greatly the efficiency of early-warning and rescue before and after the event. This paper will get to basic concept of national emergency communication engineering firstly, introducing its meaning and task; then it will make contrast, analysis and study between current situations of emergency communication engineering both domestic and abroad; finally, it will put forward the strategies and ideas concerning the future development of China's emergency communication engineering based on the combination of development experience of developed countries with advanced technology and concrete conditions of China.
\end{abstract}

Keywords: national emergency, communication engineering, emergency communication, development strategy

\section{Introduction}

Since the new millennium, our country has been attacked by various major sudden disasters, which has caused a series of major accidents with casualties and economic loss and raised higher and more updated requirements to the construction of emergency communication system in our country. After the Wenchuan massive earthquake in 2008, the national emergency communication team tried their best to restore the communication line connecting 109 towns in 7 counties where were severely afflicted as soon as possible and maintained the lifeline of communication for earthquake relief work. However, many problems were exposed, such as communication jam and occasional interruption of communication in severely afflicted areas. After being tested by many major events and continuous improvement, the emergency communication system in our country accomplished the emergency communication task successfully under the central leading body of the Party in following major and mega-disasters such as rain and snow disaster in southern China, Yushu earthquake and significant national events including Beijing Olympic Games, Shanghai World Expo and 60th anniversary of China, guaranteeing the safety of people's life and property, maintaining the harmonization and stability of society.

While gaining some achievements in the construction of national emergency communication engineering, we should also continue to think how to further construct and improve national emergency communication engineering, how to strengthen the daily maintenance and deploy and open the emergency communication devices in time effectively, and how to ensure the safety, continuity, high efficiency and stability of 
communication engineering network when facing these major sudden events.

\section{Introduction of national emergency engineering Risk Identification}

(1) Concept of national emergency communication

As an important part of national public safety emergency work, national emergency engineering is a significant means of insurance, which concerns the overall function of emergency management system and has vital significance to the guarantee of economic and social development, national security and safety of people's life and property. National emergency communication means realizing communication and assuring the safety and smooth of national significant communication when emergencies including natural disasters, accidents, social safety events and public health emergency occur through work including prevention and early-warning, emergency response and later management. Daily work also contains: improving plans, system, mechanism and laws of emergency communication, perfecting management system and comprehensive supporting system, enhancing the ability of network guarantee, equipment and reservation, as well as organizing professional guaranteeing teams.

(2) Tasks of national emergency communication

The development of national emergency communication technology and construction of communication system can't be separated from the development of society and technology. Besides, different agencies may have different understanding of emergency communication. National emergency communication engineering construction will be improved and developed continuously along with the revolution of communication industry and technology. From the perspective of function and nature, national emergency communication system is an important supplement of public communication network. The tasks of emergency communication system contains three aspects: (1) providing supplement service to public communication network in usual time; (2) providing communication guarantee to emergent events, which is also the main task of emergency communication; (3) providing support in war-time. Tasks of emergency communication could be divided into emergency service and emergency guarantee based on their nature. Emergency service refers to providing support to scheduled major social, economic and diplomatic activities; while emergency guarantee mainly means providing communication guarantee to emergent public events and natural disasters.

\section{Current situation of emergency communication engineering construction both home and abroad}

(1) Current situation of emergency communication engineering construction in China. The development of China's emergency communication could be divided into 3 phrases: the first one is years before 1998, the second one is 1998 2003 and the third one is 2003 2008. Among the above, there are three landmarks: floodrelief in 1998 and reform of Ministry of Information Industry; the war against SARS in 2004, during which the preparation of emergency plan was held as standard by the State Council; the last one is the earthquake relief work in 2008. The research on relevant standards of emergency communication was officially initiated in 2004 by China and the content is about the comprehensive system and standards of emergency communication, requirements for public communication network to support emergency communication, emergency call for special business and etc. In current stage, an emergency communication guaranteeing network has 
been primarily formed on the basis of six operators including "China Telecom, China Mobile, China Unicom, China Netcom, China Sitcom and ChinaTieTong". Besides, a new communication means has been innovated, thus the integration of six major emergency communication modes containing "fixed telephone network, mobile communication network, emergency satellite communication, emergency set, Internet emergency communication and combination of communication modes" has been basically satisfied.

However, there are some shortages existing in the construction of China's emergency communication while some achievements have been gained.

Firstly,emergency management mechanism is unreasonable and the information construction of national disaster emergency management lags behind, while the management, scheduling and operation of national emergency communication isn't fluent. Secondly, the funding of emergency communication planning, construction and maintenance is widely insufficient. Thirdly, the cable communication lines of communication operators lack microwave and satellites as standby devices and need unified standard.

(2) Learning from emergency communication engineering experiences of advanced foreign countries. National emergency communication engineering construction has been the focus of international society and huge human forces and materials have been thrown by all countries, especially European countries, America and Japan into the construction. America began to construct emergency communication networks with a lowest limit since 1970s in order to ensure the operation and scheduling of American authority facing emergencies. In America, it's typical for US government to realize the communication between governments to the public and get feedbacks from the public through the public response system (PRS system).

As a country prone to natural disasters, Japan has constructed infrastructure of emergency communication network by its primary telecom operator NTT company through many years, and a Trinitarian communication system of "network, information platform and special disaster prevention net". During the promotion of disaster network, Japan government sets up various disaster information websites.

In aspect of emergency communication management mode, both Japan and America take emergency communication as an important supplement to the public network communication and implement construction and management to it via centralized management, which is mainly shouldered by state-owned telecom operators guided by the country. Operators carry out construction and guarantee per nation's requirement while the huge expenses for research and application shall be allocated, arranged and listed by the defense department of the nation.

Through analysis of current situations of emergency communication engineering in America and Japan, we can find that it is a long and complicated process to construct the national emergency communication engineering. Firstly, it needs more focus and corresponsive resource investment of nations and needs nations to establish a reasonable and sound construction plan and management system of emergency communication engineering in order to ensure its long and lasting development; secondly, the construction of emergency communication should combine features of emergencies to meet requirements of "early prognosis, coverage of whole net, multinetwork integration and stereo information"; thirdly, the nation should coordinate with local governments and form a characteristic taking national emergency communication engineering as backbone and making local emergency communication a supplement 
with its own features; fourthly, guarantee the special network for special use and timely response, construct a information transmitting channel specially for emergency communication engineering.

\section{Development strategy of national emergency communication engineering construction}

Combine international experience of advanced countries and shortages of China's emergency communication engineering construction, the writer put forward strategies for China's emergency communication engineering construction from two aspects: management mode and technology research and development.

(1) Management mode strategy of national emergency communication engineering. Firstly, fasten the construction of national emergency communication engineering, enact corresponsive system for organization and management and rules for implementation, and build a four-level emergency communication management mode of "state, province, communication operator and county".
Secondly, set emergency communication working teams in emergency centers of nation, provinces and counties to be responsible for organizing and coordinating emergency communication work of various levels. Emergency communication working teams should be responsible for coordinating emergency work of communication management bureau, stateowned enterprise, public security, water conservancy, electricity and traffic departments, integrating information resources of emergency communication, classify jurisdictions of provinces and cities while responsible to report emergencies to higher level. Main job of emergency communication working team runs through four phrases of "prevention, preparation, response and restoration", including resource integration, funding budget, hazard identification, risk assessment, risks control, fund accounting, impact assessment, site clearing, returning to normal and plan review, among which, integration of emergency resources from different departments should be a major task of emergency communication working team.

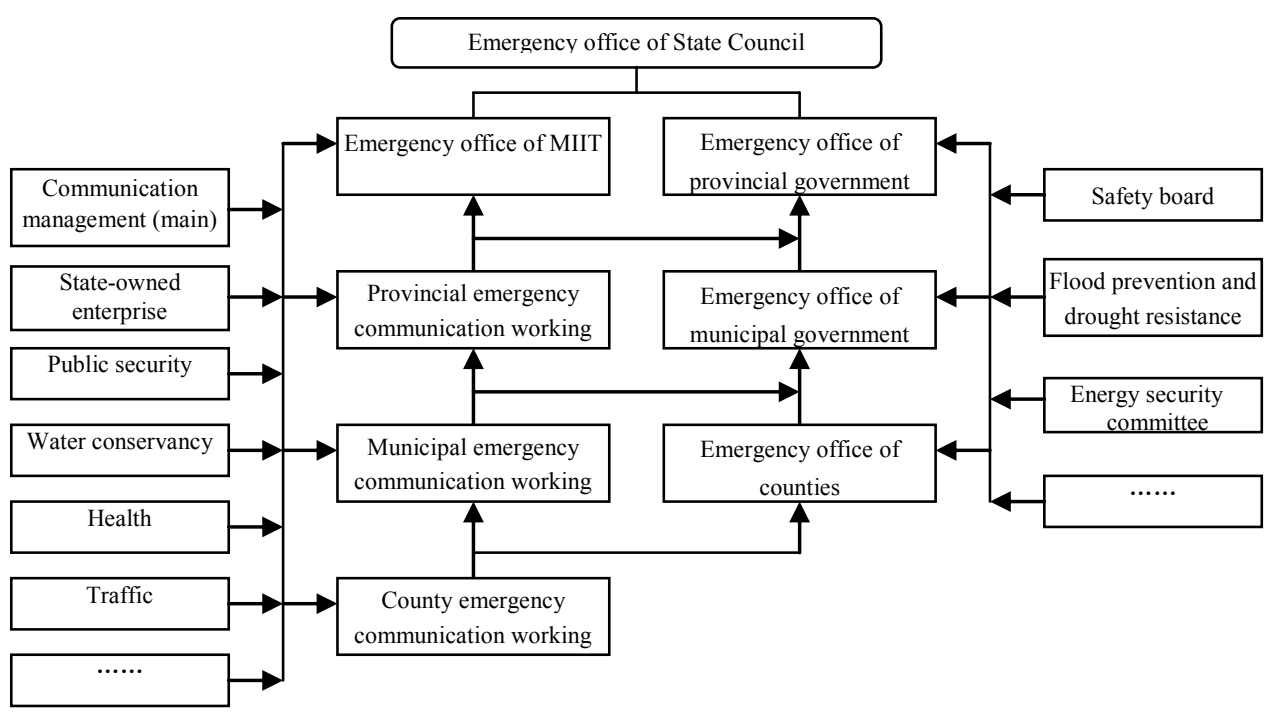

Figure.1: Organizational chart of national emergency communication 
Thirdly, establish and improve construction standard of communication operators' double line standby emergency communication. Combine national Telecom network security prevention grade assessment, help communication management bureau to establish working rules for public communication network emergency communication, breakthrough internal operation system of enterprises, request enterprises to set up a double-line emergency communication guaranteeing system with unified standards, prepare and revise emergency plans with detailed measures. Double-line emergency guarantee mainly combines wire and wireless network and presents differences between lines for public and emergency uses. Wire line refers to the communication devices constructed by operators while wireless line means digital trunked technology, satellite and radio technology. During usual time, both the two lines work for civil use while during wartime, wireless line shoulders emergency communication task by itself and works for both civil and war use.

Fourthly, establish incentive system for communication operators. After setting up well the working rules of public communication network, questionnaire method, expert method and analytic hierarchy process could be used to set up objective and scientific evaluation index, establish normative assessment system, carry out regular assessments about emergency communication guaranteeing ability to operators and include emergency ability index into the examination system of enterprises' work performance.

(2) Development strategy of national emergency communication engineering technology. Firstly, increase input for scientific research and intensity of applying research achievements to emergency communication engineering. Technology is the only drive for lasting development. Now the emergency communication of our country increases the research input for voice satellite, fastens digital trunk research, focuses on research and development of portable mobile emergency communication cars, and forms an emergency communication technology guaranteeing mode with satellite technology and digital trunk technology as double supports, mobile cars as supplements. Try to learn from experiences of America and Japan to promote RFID searching technology and GPS mobile positioning system to the market.

Secondly, establish a wholly covered, stereo and modern national emergency communication operation platform of "airearth-network". Establishment of emergency communication operation platform will favor the unified coordination and operation of all technologies and departments, guarantee the transmitting fluency of information and data. Now, all ministries and commissions have their own emergency platforms, but all those platforms would usually become separated ones when facing highly comprehensive emergencies. China government pay high attention to comprehensive emergency communication operation platform and issued Guidance to Construction of National Emergency Platform System, which put forward requirements to general frame content and labor division of construction task of national emergency platform system construction, suggesting to realize the information transmitting between accident sites and national security production emergency rescue command center via means of satellites, cellular mobile communications or trunks. The construction of national comprehensive emergency communication commanding platform should be supported by government agencies while technological and network guarantee should be provided by major communication enterprises and transmitting of information should be accomplished through an integration of many modes (see Figure 2). 


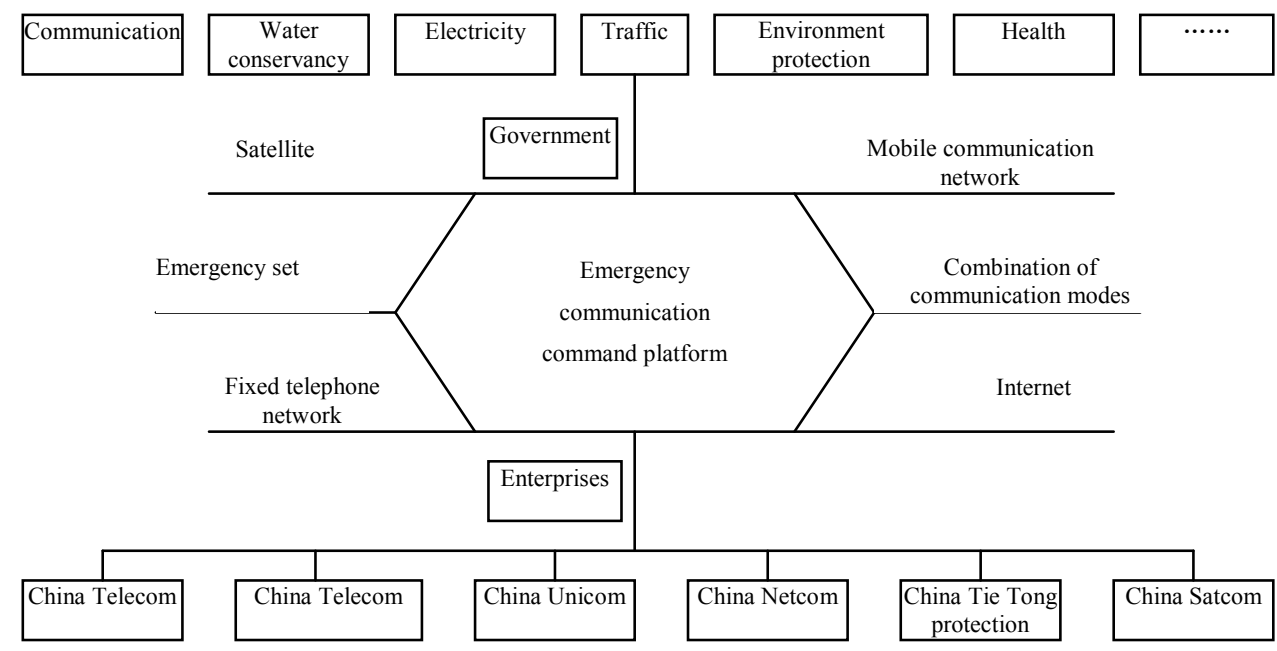

Figure.2: National emergency communication command platform

Thirdly, promote actively training and education of talents for emergency communication. Although there is rich education resource and human resource with high education in China, the professional talents of emergency management is insufficient. Education of emergency communication talents in universities is mostly limited to postgraduates, which obstructs severely the construction process of emergency communication talents with high quality. For administrative agencies of governments, there are some feasible methods as flows: the first one is to set up emergency communication majors for undergraduates and junior college students; the second one is to cultivate masters of engineering; the third one is to open senior seminars of emergency communication; the fourth one is to establish training practice base in relevant enterprises.

\section{References}

[1] Song Ying-hua. Introduction to
Emergency Management[M]. China

Economic Publishing House, 2009.

[2] www.miit.gov.cn. MIIT launched to choose identification collection of "National emergency communication". http://www.gov.cn/gzdt/201111/17/content 1995958.htm.

[3] Wang Hai-tao. Analysis on Current Status of Emergency Communication and Its Technical Means[J].

Telecommunications for Electric Power System, 2011,32(220).

[4] Xi Yu-jiu. Several Suggestions About Implementation of Emergency Communication for Natural Disasters[J]. Digital communication World, 2009, (10).

[5] Wan Xiao-yu, etc. On the National Emergency Communication Management of Serious Natural Disaster[J]. Journal of Chongqing University of Posts and Telecommunications (Social Science), 2009,21(1). 